\title{
Between Natural Language and Mathematical Symbols $(<,>,=)$ : The Comprehension of Pre-Service and Preschool Teachers- Perspective of Numbers
}

\author{
Dina Hassidov ${ }^{1}$, Bat-Sheva Ilany² \\ ${ }^{1}$ Western Galilee College, Acre, Israel \\ ${ }^{2}$ Hemdat Hadarom College, Netivot, Israel \\ Email: hasidov@netvision.net.il,bat77i@gmail.com
}

How to cite this paper: Hassidov, D., \& Ilany, B. (2017). Between Natural Language and Mathematical Symbols $(<,>,=)$ : The Comprehension of Pre-Service and Preschool Teachers-Perspective of Numbers. Creative Education, 8, 1903-1911. https://doi.org/10.4236/ce.2017.812130

Received: July 11, 2017

Accepted: September 24, 2017

Published: September 27, 2017

Copyright $\odot 2017$ by authors and Scientific Research Publishing Inc. This work is licensed under the Creative Commons Attribution International License (CC BY 4.0).

http://creativecommons.org/licenses/by/4.0/

\begin{abstract}
This article presents a quantitative and qualitative study comparing how pre-service and preschool teachers perceive the relational symbols $(<,>$ and $=)$, perspective of numbers. The study population comprised 71 pre-service teachers participating in a course dedicated to teaching and learning early childhood mathematics and 149 in-service preschool teachers. A large proportion of the participants did not answer the questions correctly or give suitable reasons for their answers. There was a significant difference between the two groups, with the pre-service teachers giving a significantly greater number of correct answers and explanations. The conclusions arising from this study are that preschool teachers do not correctly comprehend the true significance of $\langle,>$, and $=$, and therefore are unlikely to teach them correctly.
\end{abstract}

\section{Keywords}

Preschool Teachers, Pre-Service teachers, Mathematics Education, Early

Childhood, Mathematical Symbol

\section{Introduction and Theoretical Background}

\subsection{Mathematical Language in Early Childhood}

Mathematical language is a language of symbols, concepts, definitions, and theorems that does not develop naturally like a child's natural language but needs to be taught (Ilany \& Margolin, 2010). Today's global trend is to introduce "formal" mathematics at a young age. In essence, children are engaged in ma- 
thematics in daily life from birth, and preschool math practice aims to develop that awareness and cultivate mathematical thinking from an early age, shaping the child's future mathematical thinking, general thinking, and cognitive abilities (Baroody, 2000). Studies have shown that the volume and quality of preschool math practice predict a child's success in math in elementary school (Clements \& Sarama, 2006).

According to the accepted Israeli curriculum, first skills include being able to use the concepts (not the actual symbols) of "bigger", "smaller," and "equal to" to recognize differences between objects. Preschool teachers also teach the mathematical symbols already in kindergarten. But it is important that they do it correctly. Many activities for young children in preschool ask them to compare nonmathematical objects using mathematical relational symbols (i.e. $=,<,>$ ). Unfortunately, this practice teaches them that such symbols are not restricted to mathematics, leading them to use such symbols incorrectly between numbers. For example, a child in grade one may write " $6<4$ " because the four looks bigger and thicker than the six, indicating that he sees the numbers to be graphical entities and not mathematical ones. Such instances have led to investigating how pre-service and preschool teachers themselves use these mathematical symbols (Ilany \& Hassidov, 2012).

\subsection{The Development of Symbolic Understanding in Early Childhood}

The early development of symbolic reasoning and understanding by children should allow them to properly use these symbols later in formal math. Symbolic reasoning means having the ability to grasp the meaning of a symbol representing an object or idea, without having an expression in the symbol itself (Bialystok, 1992). Symbolic thinking is an evolving ability and one of the developing expressions of thought (Thomas, Jolley, Robinson, \& Champion, 1999). The development of symbolic thinking is characterized by changes that occur in the form of the mental representation. Young children believe that the symbolic representation reflects the nature of the object it represents (Bialystok, 1992), and may write the names of large objects using large letters or represent groups of multiple objects using repeated letters or words (Thomas et al., 1999). Nemirovsky \& Monk (2000) noted that young children do not distinguish between the symbol and the object that the symbol represents. This study relates to understanding the concepts of $>,<$, and $=$, which represent part of the symbolic thinking that is considered a foundation of mathematical language.

\subsection{Teaching Mathematics by Pre-School Teachers}

Preschool teachers often use the knowledge and experience they bring from daily life, meaning that they might not always give the correct mathematical importance to the symbol. If the teacher incorrectly understands the use of the symbol, she or he will subsequently pass this on to the children, leading to their incorrect 
use in the future. It is thus crucial to teach the proper mathematic clause of symbols from preschool.

Although young children can identify symbols and write them, this does not necessarily reflect an understanding of the symbols' mathematical meaning or their relationship to numbers. The concept of equality is an especially difficult concept to comprehend for children, since this term can be used both relationally and mathematically. Using the " $=$ " symbol incorrectly with children makes it even harder for them to properly understand its concept.

Many studies have examined how pre-service teachers of various ages comprehend the "equal" sign (e.g. Mark-Zigdon \& Tirosh, 2008). They show that children aged $5-12$ tend to perceive the equal sign as an operational symbol and not as a sign of comparison. Pre-service teachers translate the symbols as a command to perform a mathematical operation. It is important to grasp that the meaning of a symbol cannot be changed by non-mathematical factors (such as a change in size or other physical factor).

\subsection{Teaching Mathematics to Pre-Schoolers}

Teaching mathematics to pre-schoolers today requires professional knowledge on the part of the teachers (Charalambous, Panaoura, \& Philippou, 2009). Unfortunately, studies conducted in recent years indicate that teachers assigned with teaching preschool mathematics do not have adequate knowledge. This may stem from negative personal experiences or a lack of appropriate training in college (Tirosh \& Graeber, 1990; Hassidov \& Ilany, 2014; 2015).

\section{Research Questions}

This study set out to focus on a number of hypotheses regarding the comprehension of relational concepts $(<,>,=)$ by pre-service and Preschool teachers. In particular, we postulated the following:

1) How do pre-service teachers and preschool teachers comprehend and use the relational symbols $(>,<$, and $=)$ in perspective of numbers?

2) Is there any difference between how the two groups comprehend and use these symbols?

\section{Method}

\subsection{Population}

The study population comprised 71 second- or third-year pre-service teachers in a year-long course dedicated to the teaching and learning of mathematics in early childhood and 149 preschool expert teachers.

\subsection{Research Tools}

The data for this study were collected through questionnaires and semi-structured interviews. The 25-item questionnaire was designed by the authors as part of a larger study examining the perceptions of mathematical symbols. Four questions 
(Questions 7, 9, 10, and 16) that address mathematical symbols between different types of numbers (fractions, identical numbers, different numbers, and mathematical expressions) were analyzed. In each question, there were differences in the sizes and thicknesses of the numbers. Respondents had to add one of the relational symbols between the two numbers or indicate " $\mathrm{X}$ " if they believed there was no appropriate answer. They were asked to give the reasons for their answers. Analysis was both qualitative and quantitative.

\subsection{Procedure}

Stage 1: Testing pre-service teachers. Questionnaires were filled out by the pre-service teachers before any formal study of the subject. The researchers interviewed a random sampling of 30 pre-service teachers. This was followed by a class discussion on the use and meaning of mathematical symbols, and the subject's place in the preschool curriculum.

Stage 2: Testing preschool teachers. Each pre-service teacher gave the questionnaire to two or three preschool teachers and then conducted individual interviews to ascertain the teachers reasoning for their answers. They then discussed the meanings of the symbols with the teachers. Relevant background information was also collected.

\section{Results}

\subsection{Overall Difference}

The pre-service teachers showed a greater understanding of the unique mathematical function of the relational symbols; the preschool teachers indicated that they believed the symbols could also be used for non-mathematical comparisons.

\subsection{Question 7}

Asked to place a relational symbol between " $1 / 4$ " and " $1 / 2$ ", where the size of the " $1 / 4$ " was perceptibly larger than that of the " $1 / 2$ ".

Table 1 shows that most of the participants answered correctly (97.2\% of the pre-service teachers and $80.5 \%$ of teachers, $\mathrm{p}<0.001)$ and Table 2 shows a breakdown of their justifications.

Most of the participants who answered correctly attributed their answer to the placement of $1 / 2$ and $1 / 4$ in the sequence of numbers, or pointed out that $1 / 2$ is larger because it takes two $1 / 4$ 's to make a half. One teacher explained it as follows: "A half is greater than a quarter because if you cut one apple in half and another

Table 1. Question 7: Analysis of the mathematical symbols.

\begin{tabular}{|c|c|c|c|c|c|c|c|c|}
\hline \multirow{2}{*}{ Question 7: 1/2 $\square \mathbf{1 / 4}$} & \multicolumn{2}{|c|}{$<$} & \multicolumn{2}{|c|}{$=$} & \multicolumn{2}{|c|}{$>$ (correct) } & \multicolumn{2}{|c|}{$\mathrm{X}$} \\
\hline & $\%$ & $\mathrm{~N}$ & $\%$ & $\mathrm{~N}$ & $\%$ & $\mathrm{~N}$ & $\%$ & $\mathrm{~N}$ \\
\hline Pre-service teachers $\mathrm{N}=71$ & 0 & 0 & 0 & 0 & 97.2 & 69 & 2.8 & 2 \\
\hline Preschool teachers $\mathrm{N}=149$ & 14.1 & 21 & 0.7 & 1 & 80.5 & 120 & 4.7 & 7 \\
\hline
\end{tabular}


Table 2. Analysis of arguments for answers to Question 7.

\begin{tabular}{ccccc}
\hline Question 7: $1 / 2 \square \mathbf{1 / 4}$ & \multicolumn{2}{c}{ Pre-service teachers } & \multicolumn{2}{c}{ Teachers N $=149$} \\
\hline Justification & $\%$ & $\mathrm{~N}=71$ & $\%$ & $\mathrm{~N}$ \\
Correctly answered & Pre-service teachers & 68 & Teachers & 120 \\
None given. & 19.7 & 14 & 49.7 & 74 \\
The sequence of numbers. & 18.3 & 13 & 2.7 & 4 \\
A quarter plus a quarter equals half. & 11.3 & 8 & 2.0 & 3 \\
Because half is greater than a quarter. & 32.4 & 23 & 12.8 & 19 \\
Based on number of items. & 14.1 & 10 & 13.4 & 20 \\
Incorrectly answered & Pre-service teachers & 3 & Teacher & 29 \\
None given. & 0 & 0 & 14.1 & 21 \\
The $1 / 4$ is larger according to the picture & 4.2 & 3 & 0 & 0 \\
but $1 / 2$ is larger according to quantity. & 0 & 0 & 0.7 & 1 \\
Based on graphic property. & 0 & 0 & 4.7 & 7 \\
We never learned fractions. & & &
\end{tabular}

apple into four, the pieces of the apple cut in half are larger than that of the apple cut into four."

Table 2 shows that $14.1 \%$ of the preschool teachers answered that $1 / 2$ is smaller than $1 / 4$ but did not justify their answer, and a significant percentage, $4.7 \%$, answered that they had not yet learned the subject, indicating a void in basic intuitive knowledge of fractions. $4.2 \%$ of the pre-service teachers answered that there was no definitive answer because although $1 / 2$ is numerically larger than $1 / 4$, the physical size of the $1 / 4$ is larger than the $1 / 2$ and therefore there was no clear-cut answer. A significant percentage answered that they had not yet learned the subject, indicating a void in basic intuitive knowledge of fractions.

\subsection{Question 9}

Asked which mathematical symbol should be put between two "fives". This question deals with knowledge of the first ten numbers. The results are in Table 3.

Table 3 shows that $77.5 \%$ of the pre-service teachers and $70.5 \%$ of the teachers ( $p>0.05$ ) answered correctly, but as can be seen in Table 4 , only $45.1 \%$ of the pre-service teachers and $16.1 \%$ of the teachers who answered correctly gave the correct explanation. Of those who gave an incorrect explanation, $2.8 \%$ of the pre-service teachers and $13.4 \%$ of the teachers gave the reason to be the graphic form of the numbers, and $12.7 \%$ of pre-service teachers and $4.7 \%$ of the teachers referred to the quantity of items (one numeral) on each side. One reason given by a teacher indicated her deliberation between the graphic or numerical quality of the numbers: "It depends on how one looks at the question: according to shape, one is larger than the other; according to numerical value, they are equal."

Of those who answered incorrectly, $8.5 \%$ of the pre-service teachers and $1.3 \%$ 
of the teachers argued that no mark could be put between the digits because there can be multiple answers based on how one looked at the question ("Both numbers have the same value but not the same size and thickness"). $11.3 \%$ of the pre-service teachers and $11.4 \%$ of the teachers argued the number on the left is larger. One pre-service teachers wrote: "Looking at the numbers, they are equal in terms of quantity or value, but the type is bigger and it's confusing."

Table 3. Analysis of the mathematical symbols used to answer Question 9.

\begin{tabular}{|c|c|c|c|c|c|c|c|c|}
\hline \multirow[t]{2}{*}{ Question 9: 5 口 5} & \multicolumn{2}{|c|}{$<$} & \multicolumn{2}{|c|}{$=($ correct $)$} & \multicolumn{2}{|c|}{$>$} & \multicolumn{2}{|c|}{$\mathrm{X}$} \\
\hline & $\%$ & $\mathrm{~N}$ & $\%$ & $\mathrm{~N}$ & $\%$ & $\mathrm{~N}$ & $\%$ & $\mathrm{~N}$ \\
\hline pre-service teachers $\mathrm{N}=71$ & 0 & 0 & 77.5 & 55 & 14.1 & 10 & 8.4 & 6 \\
\hline Preschool teachers $\mathrm{N}=149$ & 0 & 0 & 70.5 & 105 & 26.2 & 39 & 3.3 & 5 \\
\hline
\end{tabular}

$[\mathrm{t}=0.716, \mathrm{p}>0.05]$

Table 4. Analysis of justification for answers to Question 9.

\begin{tabular}{|c|c|c|c|c|}
\hline \multirow{2}{*}{$\begin{array}{c}\text { Question 9: } 5 \square 5 \\
\text { Justification }\end{array}$} & \multicolumn{2}{|c|}{ Pre-service teachers $N=71$} & \multicolumn{2}{|c|}{ Teachers $\mathrm{N}=149$} \\
\hline & $\%$ & $\mathrm{~N}$ & $\%$ & $\mathrm{~N}$ \\
\hline Correctly answered & Pre-service teachers & 55 & Teachers & 105 \\
\hline None given. & 16.9 & 12 & 36.2 & 54 \\
\hline The sequence of numbers. & 45.1 & 32 & 16.1 & 24 \\
\hline $\begin{array}{c}\text { Incorrect reason } \\
\text { (Based on graphic property). }\end{array}$ & 2.8 & 2 & 13.4 & 20 \\
\hline Based on number of items. & 12.7 & 9 & 4.7 & 7 \\
\hline Incorrectly answered & Pre-service teachers & 16 & Teachers & 44 \\
\hline None given & 2.8 & 2 & 16.8 & 25 \\
\hline $\begin{array}{l}\text { Both have the same value but } \\
\text { differ in size and thickness. }\end{array}$ & 8.5 & 6 & 1.3 & 2 \\
\hline $\begin{array}{l}\text { The left number is larger than } \\
\text { that the right one. }\end{array}$ & 11.3 & 8 & 11.4 & 17 \\
\hline
\end{tabular}

\subsection{Question 10}

Asked for the symbol that should be put between " 6 " and " 4 ". $91.6 \%$ of the pre-service teachers answered correctly compared with $77.9 \%$ of teachers (Table $5, \mathrm{p}<0.01)$. In Table 6 we see that $63.4 \%$ of the pre-service teachers and $24.8 \%$ of the teachers correctly explained that it was due to the sequence of numbers. Some participants ( $8.5 \%$ of pre-service teachers, $5.4 \%$ of teachers) incorrectly based their answer on the number of items on each side and not their numerical value.

Of the incorrect answers, $17.4 \%$ of the teachers, but only $2.8 \%$ of the pre-service teachers answered that "four" was larger than "six" based on the numbers' graphic properties. 
Table 5. Analysis of the mathematical symbols used to answer Question 10.

\begin{tabular}{|c|c|c|c|c|c|c|c|c|}
\hline \multirow[t]{2}{*}{ Question 10: $6 \square \mathbf{4}$} & \multicolumn{2}{|c|}{$<$} & \multicolumn{2}{|c|}{$=$} & \multicolumn{2}{|c|}{$>$ (correct) } & \multicolumn{2}{|c|}{$\mathrm{X}$} \\
\hline & $\%$ & $\mathrm{~N}$ & $\%$ & $\mathrm{~N}$ & $\%$ & $\mathrm{~N}$ & $\%$ & $\mathrm{~N}$ \\
\hline Pre-service teachers $\mathrm{N}=71$ & 2.8 & 2 & 0 & 0 & 91.6 & 65 & 5.6 & 4 \\
\hline Preschool teachers $\mathrm{N}=149$ & 17.4 & 26 & 0 & 0 & 77.9 & 116 & 4.7 & 7 \\
\hline
\end{tabular}

Table 6. Analysis of justification for answers to Question 10.

\begin{tabular}{|c|c|c|c|c|}
\hline \multirow{2}{*}{$\begin{array}{c}\text { Question 10: } 6 \square \mathbf{4} \\
\text { Justification }\end{array}$} & \multicolumn{2}{|c|}{ Pre-service teachers $N=71$} & \multicolumn{2}{|c|}{ Teachers N = 149} \\
\hline & $\%$ & $\mathrm{~N}$ & $\%$ & $\mathrm{~N}$ \\
\hline Correctly answered & Pre-service teachers & 65 & Teachers & 116 \\
\hline None given & 19.7 & 14 & 47 & 70 \\
\hline The sequence of numbers. & 63.4 & 45 & 24.8 & 37 \\
\hline Incorrect justification. & 0 & 0 & 0.7 & 1 \\
\hline Based on number of items. & 8.5 & 6 & 5.4 & 8 \\
\hline Incorrectly answered & Pre-service teachers & 6 & Teachers & 33 \\
\hline None given & 0 & 0 & 14.1 & 21 \\
\hline $\begin{array}{c}\text { There is no answer because } 4 \text { is } \\
\text { graphically larger but } 6 \text { is } \\
\text { numerically larger. }\end{array}$ & 5.6 & 4 & 0.7 & 1 \\
\hline The 4 is larger because of the size. & 2.8 & 2 & 7.4 & 11 \\
\hline
\end{tabular}

\subsection{Question 16}

Asked which mathematical symbol should be placed between 6 and $2 \times 3$, a question that deals with mathematical problems within the first ten numbers. 98.6\% of the pre-service teachers answered correctly compared with $86 \%$ of teachers $(\mathrm{p}<0.01)$. Of the $21(14 \%)$ of teachers who answered incorrectly, 10 answered " $X$ ", claiming that a number of answers were possible, and $9(6 \%)$ claimed that $2 \times 3$ was greater than 6 due to the graphic properties of the numerals (Table 7 and Table 8).

Additional findings: Interviews and discussions with the pre-service teachers and teachers revealed that some thought it was possible to use more than one mathematical symbol as an answer.

Table 7. Analysis of the mathematical symbols used to answer Question 16.

\begin{tabular}{|c|c|c|c|c|c|c|c|c|}
\hline \multirow[t]{2}{*}{ Question 16: $2 \times 3 \square 6$} & \multicolumn{2}{|c|}{$<$} & \multicolumn{2}{|c|}{$=($ correct $)$} & \multicolumn{2}{|c|}{$>$} & \multicolumn{2}{|c|}{$\mathrm{X}$} \\
\hline & $\%$ & $\mathrm{~N}$ & $\%$ & $\mathrm{~N}$ & $\%$ & $\mathrm{~N}$ & $\%$ & $\mathrm{~N}$ \\
\hline Pre-service teachers $\mathrm{N}=71$ & 0 & 0 & 98.6 & 70 & 0 & 0 & 1.4 & 1 \\
\hline Preschool teachers $\mathrm{N}=149$ & 1.3 & 2 & 86 & 128 & 6 & 9 & 6.7 & 10 \\
\hline
\end{tabular}

$[\mathrm{t}=3.254, \mathrm{p}<0.01]$. 
Table 8. Analysis of justification for answers to Question 16.

\begin{tabular}{ccccc}
\hline Question $16: \mathbf{2} \times \mathbf{3} \square 6$ & Pre-service teachers N $=71$ & \multicolumn{2}{c}{ Teachers N $=149$} \\
\hline Justification & $\%$ & $\mathrm{~N}$ & $\%$ & $\mathrm{~N}$ \\
Correctly answered & Pre-service teachers & 70 & Teachers & 128 \\
None given. & 22.5 & 16 & 55.7 & 83 \\
The sequence of numbers. & 53.5 & 38 & 28.9 & 43 \\
Based on quantity. & 22.5 & 16 & 1.3 & 2 \\
Incorrectly answered & Pre-service teachers & 1 & Teachers & 21 \\
None given & 0 & 0 & 8.1 & 12 \\
We didn't learn this subject & 1.4 & 1 & 2 & 3 \\
Because of the size of the numeral. & 0 & 0 & 4 & 6 \\
\hline
\end{tabular}

\subsection{Discussion and Conclusion}

The results of this study indicate that both pre-service teachers and preschool teachers have some misunderstanding regarding the appropriate use of mathematical relational symbols and believe that these symbols can also be used to indicate "greater" "smaller" and "equal" for non-mathematical items. This can be construed from the number of participants who gave incorrect answers to the four questions based on the graphical properties of the numbers and not on the numerical quality, which is the only correct way to relate to relational symbols. One would assume that all the participants know that 4 is smaller than 6 , for

example, but they were confused by the intentional dilemma introduced by the method of questioning.

The number of in-service teachers who answered incorrectly was significantly greater than the number of pre-service teachers who answered incorrectly. This may be because preschool teachers were not taught this topic during their training, even though they are expected to teach the subject in the preschool.

Not only do the results show that the participants are not clear about the unique mathematical meaning of relational symbols, they may also have a lack of understanding of the significance of a number, as indicated by their justification that if the number of items on each side are the same, the expression requires an equal sign.

It can thus be concluded that a large majority of preschool teachers do not correctly comprehend the true significance of mathematical relational symbols and, as a consequence, are not teaching them correctly. At the beginning of their mathematical journey, children write numbers in different sizes and forms and teachers who incorrectly relate to the numbers as graphical objects can mislead children to think that the size of the numeral, and not its numeric value, is important.

In addition, a teacher who relates to numbers as both numerical and graphical objects, may think that either (or both) of two different symbols can be used 
(even simultaneously), depending on the context, and they do not see a problem if a child writes $\mathbf{5}>5$, because they often use the mathematical symbol ">" to compare two non-mathematical objects when size is the deciding factor. However, preschool teachers have to understand the cognitive conflict that this introduces to children, who must learn that there is always only one correct symbol that can be used between two numbers (Ilany \& Hassidov, 2012). The use of identical words (greater/smaller) in everyday life and in mathematics leads to misconceptions in the meaning of the mathematical symbols (Ilany \& Margolin, 2010).

\section{References}

Baroody, A. J. (2000). Does Mathematics Instruction for 3-to-5-Year Olds Really Make Sense? Young Children, 55, 61-67.

Bialystok, E. (1992). Symbolic Representation of Letters and Numbers. Cognitive Development, 7, 301-316. https://doi.org/10.1016/0885-2014(92)90018-M

Charalambous, C. Y., Panaoura, A., \& Philippou, G. (2009). Using the History of Mathematics to Induce Changes in Pre-Service Teachers' Beliefs and Attitudes: Insights from Evaluating a Teacher Education Program. Educational Studies in Mathematics, 71, 161-180. https://doi.org/10.1007/s10649-008-9170-0

Clements, D. H., \& Sarama, J. (2006). Young Children Mathematical Mind. Scholastic Parent \& Child, 2006, 30-37.

Hassidov, D., \& Ilany, B. (2014) A Unique Program (“Senso-Math”) for Teaching Mathematics in Preschool: Evaluating Facilitator Training. Creative Education (CE), 5, 976-988. https://doi.org/10.4236/ce.2014.511112

Hassidov, D., \& Ilany, B. (2015). The "Senso-Math” Preschool Program: Successful Cooperation between Mathematics Facilitators and Preschool Teachers. Proceedings of the 39th Conference of the International Group for the Psychology of Mathematics (Vol. 3, pp. 41-48). Hobart: PME.

Ilany, B., \& Hassidov, D. (2012). The Image of $<,>$, = by Pre-School Teachers. 36th Conference of the International Group for the Psychology of Mathematics Education (Vol. 1, pp. 243). Taiwan: PME.

Ilany, B., \& Margolin, B. (2010). Language and Mathematics: Bridging between Natural Language and Mathematical Language in Solving Problems in Mathematics. Creative Education (CE), 1, 138-148 . https://doi.org/10.4236/ce.2010.13022

Mark-Zigdon, N., \& Tirosh, D. (2008). What Counts and What Does Not Count as Legitimate Arithmetic Number Sentences: The Case of Kindergarten and First Grade Children. In J. J. Kaput, M. Blanton, \& D. Carraher (Eds.), Algebra in the Early Grades (pp. 201-210). Hillsdale, NY: Lawrence Erlbaum Associates.

Nemirovsky, R., \& Monk, S. (2000). "If You Look at It the Other Way..." An Exploration into the Nature of Symbolizing. In: P. Cobb, E. Yackel, \& K. McClain (Eds.), Symbolizing and Communicating in Mathematics Classrooms: Perspectives on Discourse, Tools, and Instructional Design. Hillsdale, NJ: Lawrence Erlbaum.

Thomas, G. V., Jolley, R. P., Robinson, E. J., \& Champion, H. (1999). Realist Errors in Children'S Responses to Pictures and Words as Representations. Journal of Experimental Child Psychology, 74, 1-20.

Tirosh, D., \& Graeber, O. A. (1990). Evoking Cognitive Conflict to Explore Pre-Service Teachers' Thinking. Journal for Research in Mathematics Education, 21, 98-108. 
Submit or recommend next manuscript to SCIRP and we will provide best service for you:

Accepting pre-submission inquiries through Email, Facebook, LinkedIn, Twitter, etc. A wide selection of journals (inclusive of 9 subjects, more than 200 journals)

Providing 24-hour high-quality service

User-friendly online submission system

Fair and swift peer-review system

Efficient typesetting and proofreading procedure

Display of the result of downloads and visits, as well as the number of cited articles Maximum dissemination of your research work

Submit your manuscript at: http://papersubmission.scirp.org/

Or contact ce@scirp.org 